\title{
Documentation of vital status in the United States of America
}

\author{
Jeffrey P. Jacobs, MD, ${ }^{\mathrm{a}, \mathrm{b}}$ Courtney Yohe, MPP, ${ }^{\mathrm{c}}$ Joshua Krantz, ${ }^{\mathrm{c}}$ and Eugene H. Blackstone, MD ${ }^{\mathrm{d}, \mathrm{e}}$
}

\footnotetext{
From the a Division of Cardiovascular Surgery, Department of Surgery, Johns Hopkins All Children's Heart Institute, Johns Hopkins All Children's Hospital, and Florida Hospital for Children, Saint Petersburg, Tampa, and Orlando, Fla; the ${ }^{\mathrm{b}}$ Division of Cardiac Surgery, Department of Surgery, Johns Hopkins University School of Medicine, Baltimore, Md; ${ }^{\mathrm{c}}$ The Society of Thoracic Surgeons, Chicago, Ill; the Departments of ${ }^{\mathrm{d}}$ Thoracic and Cardiovascular Surgery and ${ }^{\mathrm{e}}$ Quantitative Health Sciences, Cleveland Clinic, Cleveland, Ohio.

Received for publication Nov 10, 2016; revisions received March 25, 2017; accepted for publication April 1, 2017; available ahead of print May 11, 2017.

Address for reprints: Jeffrey P. Jacobs, MD, Division of Cardiovascular Surgery, Johns Hopkins All Children's Hospital, 601 Fifth St S, Suite 607, Saint Petersburg, FL 33701 (E-mail: JeffJacobs@jhmi.edu).

J Thorac Cardiovasc Surg 2017;154:644-6

$0022-5223 / \$ 36.00$

Copyright (C 2017 Published by Elsevier Inc. on behalf of The American Association for Thoracic Surgery http://dx.doi.org/10.1016/j.jtcvs.2017.04.008
}

The Social Security Death Master File (SSDMF), also known as the Social Security Death Index (SSDI), is not suitable for scientific research in its current state. We read with interest the brief research report in the April 2017 issue of the Journal by Peterss and colleagues, ${ }^{1}$ which found that survivals were substantially overestimated when follow-up was conducted by query of the SSDI versus a broader institutional method of follow-up composed of SSDI and electronic medical record queries supplemented by clinical contact and obituary searches. Peterss and colleagues ${ }^{1}$ concludes that investigators should not rely on the SSDI alone for survival assessments, and they suggested that with the new limitations on the SSDI, a multimodal approach is required for survival data that are complete and accurate.

We congratulate Peterss and colleagues ${ }^{1}$ for their important analysis of a timely topic and for their appropriate and practical conclusions. What surprised us is that the demise of the SSDI 5 years ago as a reliable source of mortality information for clinical research ${ }^{2}$ was not known to Peterss and colleagues ${ }^{1}$ when they submitted their original manuscript. We are concerned that other investigators who either subscribe to the SSDI or use a web-based service may be equally unaware that the SSDMF is no longer a reasonably accurate, ${ }^{3,4}$ inexpensive, and timely source of mortality information for the United States.

We therefore believe that it is again time to review the demise of the SSDMF and the status of the search for another source of mortality information. The purpose of this expert opinion is as follows:

- to provide commentary about the brief research report by Peterss and colleagues, ${ }^{1}$

- to present the status of documentation of vital status in the United States,

- to list the options available in the United States for documenting vital status for researchers,

- to alert readers that the SSDMF is not suitable for scientific research in its current state,

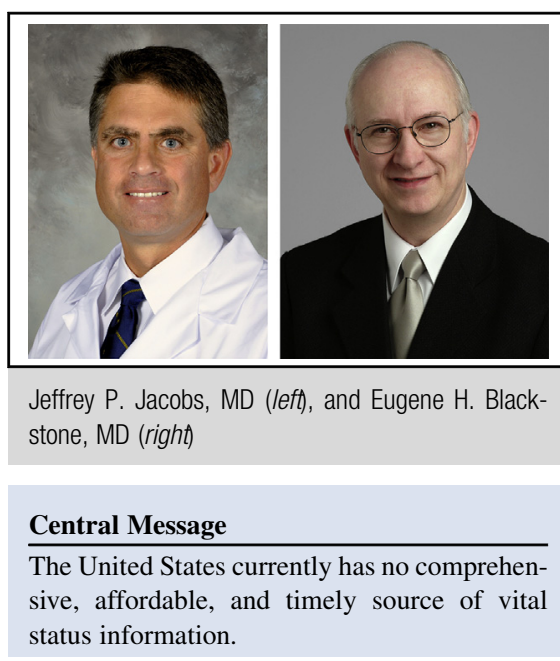

See Editorial Commentary page 647.
- to document the historical context that led to the demise of the SSDMF in November 2011,

- to summarize the efforts of professional medical societies to appeal to the federal government to resuscitate the SSDMF, and

- to describe the history and current status of alternative sources of information about vital status, none of which are ideal.

\section{BACKGROUND}

In the summer of 2011, Dr Eugene H. Blackstone received word from the administrators of the SSDMF that as of November 1, 2011, 4.2 million death records would be withdrawn from public use, and that going forward, approximately 1 million of the approximately 2.8 million death records compiled by the Social Security Administration (SSA) each year would be similarly withdrawn. Dr Blackstone, along with Dr Michael Lauer, then of the National Heart, Lung, and Blood Institute, participated in congressional hearings in which privacy advocates made a compelling case that the SSA had no right to disclose the death information received from the states. In part, the position of the privacy advocates was justified, because the agreement between the states and the SSA did not include provisions for disclosure.

The issue that we faced as clinical investigators was that the SSDMF was the only affordable registry of vital status in the United States. The National Death Index (NDI) of the Centers for Disease Control and Prevention was both more expensive and not as up to date. Basically, without 
access to the SSDMF, no affordable source of accurate national data about vital status in the United States was available to medical researchers. Dr Blackstone submitted a letter to the Journal of the American Medical Association (JAMA) to warn investigators of the impending demise of this important resource. The JAMA editors immediately placed this letter on their blog in October $2011,{ }^{5}$ and this Journal published it in January 2012 . $^{2}$

By then, a number of medical societies and investigators had been alerted, ${ }^{6}$ including The Society of Thoracic Surgeons (STS). The Centers for Disease Control and Prevention agreed to be more timely with their data in the NDI, with a lag time of no more than 18 months. What follows is a report of efforts by the STS to secure vital status information, including progress (or lack thereof) as of autumn of 2016, 5 years after the demise of the SSDMF as a vital tool for investigators.

\section{THE STS AND THE SSDMF}

The STS is interested in the documentation of vital status in the United States both to obtain longitudinal outcome data for the STS National Database and to help clinical researchers in the field of cardiothoracic surgery perform better research. In order to function as a platform for longitudinal assessment of outcomes, clinical registries must verify life status over time. The STS National Database began accessing data from the SSDMF in $2008^{7-9}$ with the goal of longitudinal ascertainment of vital status. The SSDMF contains a mix of vital status information from federal and state sources. Unfortunately, in November 2011, the SSA determined that the death information submitted by the states cannot be disclosed except to federal benefit-paying agencies and those with specific law enforcement purposes. ${ }^{2}$ The rationale for this decision by the SSA is based on the fact that states, on discovering the practices of sharing data by the SSA, objected on the basis that the federal government maintains a repository for data about death but does not actually own those data - the individual states do.

Because the information obtained from states constitutes approximately $40 \%$ of records, this restriction "renders the SSDMF useless for biomedical research." ${ }^{2}$ The decision of the SSA to rescind its policy of sharing death reports provided by individual states has resulted in the inability of the STS (and others) to access useful data about vital status from the SSDMF.

The STS has been exploring legislative and regulatory strategies to address these restrictions on the use of SSDMF data. ${ }^{10}$ In 2012, the STS began advocating for renewed SSDMF data sharing for quality improvement initiatives that meet established privacy standards. ${ }^{10}$ The STS presented this case both to Congress and to the SSA. In the 2013 Bipartisan Budget Act, a provision negotiated by Representative Paul Ryan and Senator Patty Murray was included to lock up SSDMF data for a period of 3 years after an individual's death, with only those certified by the government able to gain access to the 3-year-old data. In 2014, the STS replied to a request for information from the Commerce Department, which was charged with designing the SSDMF certification program for what was then deemed the "public DMF" database (or all SSDMF data that were more than 3 years old). ${ }^{10}$ The STS did not apply to be certified, because the available data in the "public DMF" database were 3 years old and therefore not timely enough to meet the needs of our field. Instead, the STS has pushed for a certification program that would provide comprehensive access to all data from the SSDMF. In addition, the STS and other groups operating clinical data registries have been trying, unsuccessfully, to insert legislative language restoring full access to SSDMF data into the Stopping Improper Payments to Deceased People Act and other available legislative vehicles. ${ }^{10,11}$

The principal issue with using the SSDMF to verify life status in clinical registries is that states technically own the data that they report to the SSDMF. States asserted that the SSA was inappropriately sharing those data publicly and charging for this access. For several years, the STS has sought a legislative solution to this challenge; however, lawmakers are reluctant to mandate that states provide their data, even if the STS and other physician organizations are willing to pay for the access. The STS and other physician organizations do not wish to negotiate with each state individually, because such negotiations would be tremendously cumbersome.

States are working on implementing a method of electronic death reporting, called the Electronic Verification of Vital Events (EVVE) database, operated by the National Association for Public Health Statistics and Information Systems (NAPHSIS). ${ }^{12}$ According to the website maintained by NAPHSIS, "NAPHSIS is the national nonprofit organization representing the state vital records and public health statistics offices in the United States. Formed in 1933, NAPHSIS brings together more than 250 public health professionals from each state, the five territories, New York City, and the District of Columbia.... EVVE, operated by the National Association for Public Health Statistics and Information Systems (NAPHSIS), provides customers with the ability to quickly, reliably, and securely verify and certify birth and death information. Electronic inquiries from authorized users can be matched against over 250 million birth and death records from state and jurisdiction owned vital record databases nationwide. An electronic response from the state or jurisdiction either verifies or denies a match within matter of seconds. No other system on the market provides access to a more complete set of state and jurisdiction owned vital records than EVVE." 12 On September 16, 2016, STS staff met with a representative from NAPHSIS to discuss a pilot 
version of EVVE set to go live later in 2016. The EVVE database does not provide complete death data, but it begins to close the $40 \%$ gap left when the SSDMF ceased to include state-reported data. The EVVE database is updated almost instantaneously; however, not all states are currently reporting data by way of EVVE (most are expected to have reported some data to the EVVE database by the end of 2016). Further, it may still be necessary to access the data through the SSDMF certification program, described previously, to compile a complete death file.

Many have suggested using the NDI from the Centers for Disease Control and Prevention instead of the SSDMF. The STS and other physician organizations have identified several problems with using the data from the NDI to verify life status in medical registries, however, including (1) lack of timeliness of the data, (2) prohibitive pricing structure, and (3) limitation of the use of the NDI to medical or health care research (and not legal or administrative purposes), whereas the primary purpose of the STS National Database is quality improvement, which is not considered to be research but rather health care operations. ${ }^{8,13}$ The STS has been given certain assurances that the third problem listed above can be accommodated. Consequently, the STS has again recently explored accessing NDI data. The STS has found that concerns regarding the timeliness of the data have largely been resolved. Negotiations are therefore currently underway.

Finally, the Medicare Access and CHIP Reauthorization Act of 2015 includes a mandate that the Centers for Medicare and Medicaid Services share Medicare claims data. Furthermore, the SSA statute technically says that the Secretary of Health and Human Services has the authority to access all SSDMF data to ensure that improper Medicare payments are not made. Therefore, as part of the ongoing efforts of the STS to secure access to Medicare claims data, the STS also has been asking the Secretary to use this authority before sharing Medicare data with the STS. To date, the STS has not received data from the SSDMF (or Medicare) through this route. The STS continues to petition Congress for access to these data from Medicare and the SSDMF.

\section{SUMMARY}

Beginning in 1503, the Bills of Mortality for the city of London were published every Thursday. At most, vital status data were out of date by no more than 1 week. In contrast, in the United States today, the SSDMF no longer provides complete and accurate data. EVVE may one day provide a solution but is currently a work in progress, and the NDI is currently too expensive to be a reasonable tool for the verification of life status in large data sets. NDI access is affordable for smaller data sets, and EVVE may have potential in the future. Efforts to resuscitate the SSDMF should continue to be pursued, but these efforts may not be successful. Therefore, in the United States today, there remains no accurate, comprehensive, affordable, and timely single source of vital status data for medical research and quality initiatives.

\section{Conflict of Interest Statement}

Authors have nothing to disclose with regard to commercial support.

\section{References}

1. Peterss S, Charilaou P, Ziganshin BA, Elefteriades JA. Assessment of survival in retrospective studies: the Social Security Death Index is not adequate for estimation. J Thorac Cardiovasc Surg. 2017;153:899-901.

2. Blackstone EH. Demise of a vital resource. J Thorac Cardiovasc Surg. 2012;143: 37-8.

3. Boyle CA, Decouflé P. National sources of vital status information: extent of coverage and possible selectivity in reporting. Am J Epidemiol. 1990;131: $160-8$.

4. Newman TB, Brown AN. Use of commercial record linkage software and vital statistics to identify patient deaths. J Am Med Inform Assoc. 1997;4:233-7.

5. Mitka M. Changes in access to death data may impede medical research.news@ JAMA 2011. Available at: https://newsatjama.jama.com/2011/10/19/changes-inaccess-to-death-data-may-impede-medical-research/. Accessed September 28, 2016.

6. da Graca B, Filardo G, Nicewander D. Consequences for healthcare quality and research of the exclusion of records from the Death Master File. Circ Cardiovasc Qual Outcomes. 2013;6:124-8.

7. Jacobs JP, Edwards FH, Shahian DM, Prager RL, Wright CD, Puskas JD, et al. Successful linking of the Society of Thoracic Surgeons database to social security data to examine survival after cardiac operations. Ann Thorac Surg. 2011;92: 32-7; discussion 38-9.

8. Jacobs JP, Shahian DM, Edwards FH, O'Brien SM, Blackstone EH, Puskas JD, et al. Reply. Ann Thorac Surg. 2012;94:693-4.

9. Jacobs JP, O'Brien SM, Shahian DM, Edwards FH, Badhwar V, Dokholyan RS, et al. Successful linking of the Society of Thoracic Surgeons Database to Social Security data to examine the accuracy of Society of Thoracic Surgeons mortality data. J Thorac Cardiovasc Surg. 2013;145:976-83.

10. The Society of Thoracic Surgeons. Social Security Death Master File. Available at: http://www.sts.org/advocacy/record/social-security-death-masterfile. Accessed September 16, 2016.

11. Mathews BJ. Massachusetts Genealogy Council Civil Records Committee: identity theft, tax fraud, and the death master file timeline. Available at: http:// www.fgs.org/rpac/wp-content/uploads/2010/02/SSDI-timeline-19-Jan-2015.pdf. Accessed September 16, 2016.

12. National Association for Public Health Statistics and Information Systems (NAPHSIS). About EVVE. Available at: http://www.naphsis.org/evve. Accessed September 16, 2016.

13. Morales DL, McClellan AJ, Jacobs JP. Empowering a database with national long-term data about mortality: the use of national death registries. Cardiol Young. 2008;18(Suppl 2):188-95. 